\title{
REFLEXÕES PARA O DISCERNIMENTO DO ESTEREÓTIPO E A IMAGEM DO NEGRO
}

\author{
REFLECTIONS FOR THE DISCERNMENT OF THE STEREOTYPE AND THE IMAGE OF AFRICAN \\ DESCENT
}

\author{
João Grandino Rodas* \\ Celso Prudente**
}

Os autores agradecem de público o empenho e esforço de Ricardo Oliveira de Jesus, que digitou este artigo.

\begin{abstract}
Resumo:
A abordagem desta reflexão busca apontar o mito da superioridade racial, como resultado de uma ação ideológica, que encontra no estereótipo seu principal componente. Fenômeno, que se caracteriza na tentativa de aviltação da imagem do afro descendente e da sua cultura. Essa situação é construída no contexto das relações da invisibilidade do negro nos meios de comunicação de massa e, também na banalização dos personagens, vividos pelos atores de origem africana, com o propósito da negação da sua imagem em favor do eurocentrismo.

Palavras chaves: Superioridade racial. Inferioridade racial. Estereótipo. Imagem. Afrodescendente.

Abstract:

The approach of this discussion aims to point out the myth of racial superiority as a result of an ideological action, which finds in stereotypes its main component. Such phenomenon is characterized in an attempt to downgrade the image of African descents and their culture. This situation is constructed in the context of the invisibility relations of African descent in the mass communication and also trivializing the characters experienced by actors of African origin, with the main purpose of the denial of their image in favor of Eurocentrism.
\end{abstract}

Keywords: Racial superiority. Racial inferiority. Stereotypes. Images. African descent.

Em um país poliétnico de economia dependente, provavelmente, o modo de produção social também produz o modelo de seleção sócio-racial, privilegiando a matriz cultural do segmento étnico-social mais próximo do fenótipo da força configurada na expressão do imperialismo econômico. Aimé Césaire, poeta e dramaturgo negro da Martinica, um dos criadores do conceito de "negritude", entende que uma das dificuldades

\footnotetext{
Diretor da Faculdade de Direito da Universidade de São Paulo. Professor Titular de Direito Internacional do Departamento de Direito Internacional da Faculdade de Direito da Universidade de São Paulo. Jurista, Diplomata.

** Doutor em Cultura e Educação pela Universidade de São Paulo. Pesquisador do Núcleo de Estudos e Pesquisas Interdisciplinares sobre o Negro Brasileiro da Universidade de São Paulo - NEINB/USP. Antropólogo, Cineasta, Curador da Mostra Internacional do Cinema Negro.
} 
fundamentais da Europa foi ter gerado em seu próprio seio as problemáticas do proletariado e da colonização, revelando a si mesmo uma possível espécie de patologia na medida em que a existência destas contradições demonstra a sua inépcia. Assim escreve Césaire:

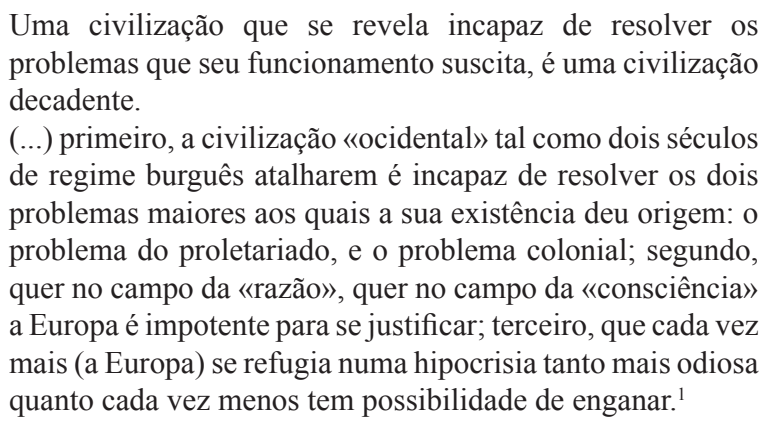

Nesta linha de discernimento, percebe-se que os traços fisionômicos e culturais fora da referência hegemônica são vitimados pela ideologia da inferioridade racial, situação consubstanciada na solércia, traduzida no equivocado entendimento, no qual estabelece uma ligação estrutural entre escravidão e inferioridade, pois a compreensão mais próxima da assertiva é inversa, na medida em que escravo é categoria econômica e inferioridade é categoria psicológica, não havendo conexão entre estes vetores em questão.

É sensato supor que a postura racista produziu a imagem negativa do afrodescendente, que se configura em um simbolismo que conota a condição profissional a partir da diferença cultural no âmbito da dicotomia etnológica, como se apreende na reflexão de Maria Lúcia Rodrigues Muller:
A hierarquização ocupacional, antes de ser reflexo de condições econômicas, era fruto do mesmo tipo de diferenciação cultural, produzida com as questões do corpo. Assim como a aparência de saúde ou de doença, de beleza ou de feiúra, eram construções simbólicas da "superioridade" e "inferioridade" raciais. Também as representações sobre a "pouca" inteligência de negros e mestiços, sua "incapacidade" (...) fazem parte de um conjunto de representações sociais, originárias da difusão das teorias racistas em voga no séc. XIX. ${ }^{2}$

Jean-Paul Sartre observa a hegemonia caucasiana por um processo de dominação milenar, na qual o opressor faz de seu olhar uma expressão hierárquica

CÉSAIRE, Aimé. Discurso sobre o colonialismo. Porto: Ed. Cadernos para o diálogo, 1971. p. 5-6.

2 MULLER, Maria Lúcia Rodrigues. A cor da escola: imagens da primeira república. Cuiabá: Ed. Universidade Federal do Mato Grosso, 2008. p. 43. 
deliberada em uma configuração vertical, colocando-a no exercício do olhar como força de poder, de tal modo a não se permitir a condição daquele que é olhado. Fenômeno, que se daria por uma reflexão, localizando-a em experiência comum, permitindo-lhe a situação horizontal, que se caracterizaria o caminhar em linhas comuns, desenhando-lhe o princípio de equidade como elemento norteador das relações possíveis. Portanto, a assimetria de posições raciais em um espaço comum, que determina as relações de referência, pautarse-á pela relação da posição racial estabelecida que, enquanto que parte, coloca-se como referência do todo. Observemos Sartre:

O que esperáveis que acontecesse, quanto tirastes a mordaça que tapava estas bocas negras? (...) Estas cabeças que nossos pais haviam dobrado pela força até o chão, pensáveis, quando se reerguessem, que leríeis adoração em seus olhos? Ei-los em pé, homens que nos olham e faço votos para que sintais como eu a comoção de ser visto. Pois o branco desfrutou durante três mil anos o privilégio de ver sem que o vissem; era puro olhar, a luz de seus olhos subtraía tôdas as coisas da sombra natal, a brancura de sua pele também era um olhar, de luz condensada. O homem branco, branco porque era homem, branco como o dia, branco como a verdade, branco como a virtude, iluminava a criação qual uma tocha, desvelava a essência secreta e branca dos seres. ${ }^{3}$

O que esperáveis que acontecesse, quanto tirastes a mordaça que tapava estas bocas negras? (...) Estas cabeças que nossos pais haviam dobrado pela força até o chão, pensáveis, quando se reerguessem, que leríeis adoração em seus olhos? Ei-los em pé, homens que nos olham e faço votos para que sintais como eu a comoção de ser visto. Pois o branco desfrutou durante três mil anos o privilégio de ver sem que o vissem; era puro olhar, a luz de seus olhos subtraía tôdas as coisas da sombra natal, a brancura de sua pele também era um olhar, de luz condensada. O homem branco, branco porque era homem, branco como o dia, branco como a verdade, branco como a virtude, iluminava a criação qual uma tocha, desvelava a essência secreta e branca dos seres. ${ }^{4}$

O que esperáveis que acontecesse, quanto tirastes a mordaça que tapava estas bocas negras? (...) Estas cabeças que nossos pais haviam dobrado pela força até o chão, pensáveis, quando se reerguessem, que leríeis adoração em seus olhos? Ei-los em pé, homens que nos olham e faço votos para que sintais como eu a comoção de ser visto. Pois o branco desfrutou durante três mil anos o privilégio de ver sem que o vissem;

\footnotetext{
SARTRE, Jean-Paul. Reflexões sobre o racismo. Tradutor J. Guinsburg. 2. ed. São Paulo: Ed. Difusão Européia do Livro, 1960. p. 105.

4 Id. Ibid.
} 
era puro olhar, a luz de seus olhos subtraía tôdas as coisas da sombra natal, a brancura de sua pele também era um olhar, de luz condensada. O homem branco, branco porque era homem, branco como o dia, branco como a verdade, branco como a virtude, iluminava a criação qual uma tocha, desvelava a essência secreta e branca dos seres. ${ }^{5}$

Ao contrário da ética homérica, que sugere a areté $^{6}$ como patrimônio exclusivo dos bem nascidos, e aqueles que, no-la, jamais poderiam titubear como garantia da ostentação da mesma, outras fabulações mitológicas apontam para a restauração da condição que, por história, bem o cabe, em caso de subtração de status, dados por cataclismas, que impõe à sua elite, a condição de subalternidade em relação a outro elemento que se constituiu em força preponderante, conforme se nota nas contradições econômicas de senhor e escravo, assim como é percebido até nas mais antigas expressões do imaginário dos Gregos.

Entretanto, o pensamento aristotélico não buscou o discernimento da contradição sociocultural da sua época, para transformá-lo em favor do bem-estar de todas as forças sociais, de então. Contudo, concorreu com exercício intelectual, no sentido de justificar a estratificação helênica, fenômeno, que se caracterizou no esforço de manutenção do status quo deste período.

Constata-se que, possivelmente, na lição de Aristóteles, o traço euro heteromasculino é referencia para a construção da imagem ideal de poder, de tal sorte que os elementos não coadunáveis com esse comportamento se tornariam traço de marginalização, consubstanciado no preconceito que daí decorreria. Nessa linha de compreensão, o lavrador não seria digno de cidadania, na medida em que desenvolvia um trabalho braçal baseado na agricultura. No Livro Quarto do clássico “A Política”, Aristóteles observa:

$\S 2$. Mas, já que estamos a examinar qual a constituição política perfeita, sendo essa constituição a que mais contribui para a felicidade da cidade, e, por outro lado, visto que já foi dito que a felicidade não poderia existir sem a virtude, é claro que um Estado perfeitamente governado e composto de cidadãos que são homens justos no sentido absoluto da palavra, e não relativamente a um sistema dado, os cidadãos não devem exercer as artes mecânicas nem as profissões mercantis; porque este gênero de vida tem qualquer cousa de vil, e é contrário à virtude. É preciso mesmo, para que sejam verdadeiramente cidadãos, que eles não se façam lavradores;

\footnotetext{
5 Id. Ibid.

${ }^{6}$ areté - exclusividade do homem de valor, o que se distingue entre os seus pares.
} 
porque o descanso lhes é necessário para fazer nascer a virtude em sua alma, e para executar os deveres civis. ${ }^{7}$

É pertinente sugerir que, o fato de Deméter, divindade grega do campo/terra, ser do sexo feminino, tenha concorrido para o preconceito contra o lavrador, localizado em uma nuance de natureza axiológica diferente do sentido de valor do modelo ideal de poder ocidental, na lógica aristotélica.

Com efeito, o escravismo era presente nos remotos pensamentos helênicos, caracterizado na mitologia grega, visto no episódio cujo Apolo, símbolo da beleza e da harmonia, teve a escravidão como represália, quando se rebelou contra o grande Zeus. Entretanto, não perdeu o status de ícone do belo e do harmônico. Na escravidão clássica, o escravo era reintegrado na sociedade que o escravizou, portanto, o poder era proibido de usar de prática como lenocínio e outras que poderiam fragmentar sua dignidade. No caso específico do Brasil, no período colonial, o Direito Romano era uma alternativa para cobrir as lacunas jurídicas. No entanto, no tocante à preservação da dignidade do escravo, tal alvitre não era considerado, talvez pelo fato de não ter em vista a reintegração do escravizado na sociedade que o escravizou, elemento basilar da escravidão clássica. Em "Preconceito Racial e Igualdade Jurídica no Brasil", a pesquisadora Eunice Prudente, chama a atenção para o fato que, a escrava que era engravidada pelo seu senhor, tinha o filho nascido livre, sendo posta em liberdade, situação que se constituía em elemento basilar do Direito Romano, que não foi considerado no escravismo brasileiro. ${ }^{8 / 9} \mathrm{Nem}$ mesmo a abolição da escravatura com a Lei Áurea se preocupou com a integração do ex-escravo na sociedade vigente, deixando-o estigmatizado com a negatividade pautada a toda sorte de um sistema de trabalho livre, que não tinha lugar para aqueles que hora vieram para servirem no trabalho compulsório. Situação que contribuiu para formação do estigma de mau cidadão, marcado pela: malandragem, prostituição, vadiagem, entre outros. A este respeito, Hélio Santos comenta:

Estigma é uma marca que assinala algo prejudicial ou infame. A presença do negro é denunciada pela cor. As dificuldades no mundo do trabalho ganham um sentido perverso para o ex-escravo após a abolição. De bom escravo, que por mais de três séculos sustentara a vida econômica do país, o negro salta para a posição de mau cidadão, agora não mais apto para bem cumprir obrigações. Assim, a vadiagem era o destino compulsório de muitos negros (...)

ARISTÓTELES. A política. Tradução de Nestor Ferreira Chaves. São Paulo: Ed. Edipro, 1995. p. 145.

\& PRUDENTE, Eunice. Preconceito racial e igualdade jurídica no Brasil. São Paulo: Ed. Julex, 1989. p. 91.

9 MALHEIRO, Agostinho Marques Perdigão. Escravidão no Brasil: ensaio histórico, jurídico, social. Rio de Janeiro: Ed. Nacional, 1866. p. 69. 
(...) É compreensível, portanto, em contexto tão adversos como esses que, em diversas ocasiões, a população negra tenha tido na prostituição e na criminalidade uma "saída" para as suas dificuldades. Daí a figura da prostituta ou da mulata gostosa, a qual é colocada sempre como disponível. Daí também a figura do meliante, do malandro e do folgado, sem ocupação. A estigmatizarão do negro o conecta diretamente à aquilo que não é certo, correto ou bom.(...). ${ }^{10}$

A escravização em nosso país foi atípica do modelo clássico, em detrimento da imagem de integridade humana do escravizado. A escravidão encontrou na superioridade racial e no mito do salvacionismo, os principais componentes da ideologia racial, com base no preconceito.

$\mathrm{O}$ ensinamento vitoriano sugere que, a repetição de algo ficcional sobre um individuo, ganha força, tornando-se realidade. Deste modo, apreende-se que subjetividade do estereótipo como elemento ideológico, concorre para formar dimensão na demanda das relações objetivas do objeto de preconceito, resultante da construção ideológica dos estereótipos. Conforme Victor Hugo:

(...) Verdade ou não, o que se diz a respeito dos homens ocupa muitas vezes em sua vida, e sobretudo em seu destino, um lugar tão importante quanto aquilo que fazem. ${ }^{11}$

Ainda tem sido recorrente a patologia comunicacional que apresenta o afrodescendente com estereótipo de inferior, sobretudo, nos principais veículos de comunicação de massa, notadamente, no cinema, rádio e televisão, que se pautam pela ausência do componente afro, ou pela presença rarefeita, configurada no tipo boçalizado, protagonizando cenas chulas humorísticas ou de núcleo novelista desavisado em relação à modernidade que, por princípio, pauta-se no respeito à diversidade. Situação que concorre para uma política psicológica dos meios de comunicação, em favor de uma imagem negativa da africanidade, contribuindo para a elevação da baixa-estima do jovem negro. Não é à toa que o cinema foi o início da psicologia moderna, pois a imagética cinematográfica, sobretudo, vê nos problemas do olhar a subjetividade da pessoa e do seu meio.

No Brasil, a Constituição, de 1988, estabelece o princípio de um estado democrático de direito, que encontra na educação, o seu principal lócus. Portanto, é imperativo que as atividades desenvolvidas no âmbito comunicacional, tenham como horizonte a consciência da igualdade e da justiça social, na linha da educação multicultural, baseada no respeito às diferenças como testemunho de garantia da cidadania. Cumpre

10 SANTOS, Hélio. A busca de um caminho para o Brasil. São Paulo: Ed. SENAC, 2001. p. 80.

11 HUGO, Victor. Os miseráveis. Trad. Regina Célia de Oliveira. São Paulo: Ed. Martin Claret, 2007. (Coleção a Obra Prima de Cada Autor. Série Ouro). p. 27. 
lembrar a Lei n. 10.639, que dispõe da obrigatoriedade do ensinamento da história da África e da cultura afro-brasileira nos diferentes níveis de ensino. Nesta linha de compreensão, em favor ao respeito da diversidade étnico-cultural da criança e do adolescente, Denise Auad, em dissertação de mestrado da Faculdade de Direito da USP, lembra que, a Convenção Internacional das Nações Unidas, sobre os direitos da criança, de 1989, preceitua, em seu art. 29, que:

1. Os Estados partes reconhecem que a educação da criança deverá estar orientada no sentido de:

c) Imbuir na criança o respeito a seus pais, à sua própria identidade cultural, a seu idioma e seus valores, aos valores nacionais do país em que reside, aos do eventual país de origem, e aos das civilizações diferentes da sua;

d) Preparar a criança para assumir uma vida responsável numa sociedade livre, com espírito de compreensão, paz, tolerância, igualdade de sexos e amizade entre todos os povos, grupos étnicos, nacionais e religiosos, e de origem indígena. $^{12}$

Conclui-se que a principal vítima do estereótipo da imagem do afrodescendente, provavelmente, são as crianças e jovens, faixas etárias fundamentais para a formação do espírito de cidadania, tão caro para uma sociedade verdadeiramente democrática.

São Paulo, novembro de 2009.

\section{Referências}

ARISTÓTELES. A politica. Tradução de Nestor Ferreira Chaves. São Paulo: Ed. Edipro, 1995.

AUADI, Denise. A cidadania da criança e do adolescente, de acordo com a atual Constituição Federal Brasileira e com a lei 8.069, de 13 de julho de 1990. 2003. Dissertação (Mestrado) Faculdade de Direito, Universidade de São Paulo, São Paulo.

CÉSAIRE, Aimé. Discurso sobre o colonialismo. Porto: Ed. Cadernos para o diálogo, 1971.

HUGO, Victor. Os miseráveis. Tradutora Regina Célia de Oliveira. São Paulo: Ed. Martin Claret, 2007. (Coleção a Obra-Prima de Cada Autor. Série Ouro).

12 AUADI, Denise. A cidadania da criança e do adolescente, de acordo com a atual Constituição Federal Brasileira e com a lei 8.069, de 13 de julho de 1990. 2003. Dissertação (Mestrado) - Faculdade de Direito, Universidade de São Paulo, São Paulo. p. 68. 
MALHEIRO, Agostinho Marques Perdigão. Escravidão no Brasil; ensaio histórico, jurídico, social. Rio de Janeiro: Ed. Nacional, 1866.

MULLER, Maria Lúcia Rodrigues. A cor da escola: imagens da primeira república. Cuiabá: Ed. Universidade Federal do Mato Grosso, 2008.

PRUDENTE, Eunice. Preconceito racial e igualdade jurídica no Brasil. São Paulo: Ed. Julex, 1989.

SANTOS, Hélio. A busca de um caminho para o Brasil. São Paulo: Ed. SENAC, 2001.

SARTRE, Jean-Paul. Reflexões sobre o racismo. Tradutor J. Guinsburg. 2. ed. São Paulo: Ed. Difusão Européia do Livro, 1960. 